\title{
EVALUATION OF DISTANCE LEARNING SYSTEM (E-LEARNING): A SYSTEMATIC LITERATURE REVIEW
}

\author{
Ignatius Adrian Mastan"), Dana Indra Sensuse ${ }^{2)}$, Ryan Randy Suryono ${ }^{3)}$, Kautsarina ${ }^{4)}$ \\ ${ }^{1,2,3,4}$ Faculty of Computer Science, Universitas Indonesia \\ ${ }^{1}$ Faculty of Technology and Design, Universitas Bunda Mulia \\ ${ }^{3}$ Faculty of Engineering and Computer Science, Universitas Teknokrat Indonesia \\ ${ }^{4}$ Ministry of Communications and Informatics, Republic of Indonesia \\ 1,2,3,4 Depok, Indonesia \\ ${ }^{1,4}$ Jakarta, Indonesia \\ ${ }^{3}$ Bandar Lampung, Indonesia
}

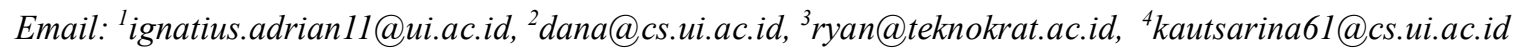

\begin{abstract}
Research in the field of e-learning is currently experiencing rapid development, especially due to the covid 19 pandemic. The application of e-learning in the world of education is currently the main thing and requires evaluation of its use. This study aims to determine the evaluation of models and trends in the development of e-learning (Learning Management System). Applying the Kitchenham approach, this System Literature Review (SLR) uses three main databases including Science Direct, ACM, SCOPUS. The final result obtained 38 articles published between 2016 and 2021. From this SLR, it was found that there were 7 criteria, namely Platform, Evaluation Model, Evaluation, Model, Approach, Problem, Trend and Challenge. These 7 criteria can be used for further research on e-learning. Thus this research provides knowledge about criteria that can be used further in research on E-learning and provides insight into its state-of-the-art.
\end{abstract}

Keyword: e-learning, learning management system, systematic literarure review

\section{Introduction}

With the outbreak of the current covid 19 pandemic, it has changed various aspects of human activity, one of the activities affected is the world of education, especially universities. Universities are required to be able to provide distance learning services that are capable of accommodating all the needs of students to conduct distance learning. Many universities do not have the readiness to conduct distance lectures, both in terms of human resources, technology infrastructure, learning systems (learning management systems / e-learning). The unpreparedness of educational institutions (Universities) when switching from traditional face-to-face lectures to distance education channels causes several problems [39]. Thus, it is necessary to conduct an evaluation of distance learning to determine the extent to which the acceptance of the distance learning system (learning management system / e-learning) is accepted by its users.

Several studies have been conducted regarding the evaluation of e-learning users (distance learning) to measure the success of using distance learning systems. Tautz has evaluated the application of digital tools (lecture recordings, question tools, classroom response systems and virtual reality) regarding the perceived impact on active learning, repetition, and feedback in Higher Education [40]. Some researchers measure the success of information system acceptance using the
DeLone and McLean model to measure the quality, system use, perceived benefits and student perspectives [40]. Other studies have been conducted to determine the acceptance factors of the COVID-19 pandemic online learning platform using the Extended Technology Acceptance Model (ETAM) and the Delone and McLean IS Success Model by testing several factors, namely the user interface (UI), perceived ease of use (PEU), perceived usefulness (PU), information quality (IQ), system quality (SQ), behavioral intention (BI), and actual use were analyzed by Structural Equation Modeling. (SEM) [41].

Therefore, this research is proposed with the aims to conduct a Systematic Literature Review (SLR) approach from SCOPUS, ACM and Science Direct database to identify the methods used by current research to evaluate distance learning (learning management system / e-learning), the results, as well as trends and issues that arise from the application of the evaluation method.

\section{Research Method}

This Systematic Literature Review (SLR) research is based on Kitchenham with the stages of planning, implementation and reporting [40]. Starting with determining the main purpose of this research, namely to know the evaluation and trend of using e-learning (Learning Management System). The next stage is to 
determine the review protocol in the form of criteria, research questions, boolean search and year ranges, types and sources of literature. To determine the research question using the PICOC Formula (Population, Intervention, Comparison, Outcome, and Context). The next stage is to determine the inclusion and exclusion criteria as well as a literature quality test checklist.

Table 1. PICOC Formula

\begin{tabular}{|l|l|}
\hline $\begin{array}{l}\text { Populasi } \\
\text { (Population) }\end{array}$ & $\begin{array}{l}\text { e-learning or distance learning or } \\
\text { learning system management }\end{array}$ \\
\hline $\begin{array}{l}\text { Intervensi } \\
\text { (Intervention) }\end{array}$ & evaluation model \\
\hline $\begin{array}{l}\text { Perbandingan } \\
\text { (Comparison) }\end{array}$ & - \\
\hline Hasil (Outcome) & trend \\
\hline Konteks (Context) & student or teacher \\
\hline
\end{tabular}

Based on the PICOC formula, the following research questions are formulated :

1. How to evaluate the use of e-learning (learning system management) to support distance learning?

2. What are the issues/trends that can emerge from the evaluation of the successful model of using e-learning in distance learning based on the relevant literature?

The Boolean search used in this study is ("elearning" OR "distance learning" OR "learning management system" AND "evaluation model" AND trend AND student OR teacher). This research focuses on research that takes place in the period 2016 to 2021, using sources from SCOPUS, ACM, and Science Direct databases that have been processed using the Mendeley Desktop application. The next stage will select the papers obtained based on the use of boolean search by using inclusion and exclusion criteria in the title and abstract. The inclusion and exclusion criteria in this study are based on the research question and the Kitchenham guidelines [42]. The kitchenham method in the Systematic Literature Review (SLR) has been used by other researchers. Suryono, et al in a research paper entitled Peer to Peer (P2P) Lending Problems and Potential Solutions: A Systematic Literature Review. This research using kitchenham method aims to identify problems in $\mathrm{P} 2 \mathrm{P}$ Lending and present alternative technical and non-technical solutions to the problems [1].

Articles containing the keywords e-learning or distance learning, obtained from several sources, namely: Scopus, ACM, and Science Direct. Of the 607 articles obtained based on searches using a boolean search, filtered based on inclusion and exclusion and checking for full articles, 38 articles were obtained that met the criteria, consisting of 3 articles for SCOPUS, 29 articles for ACM and 6 articles for Science Direct. The article screening process can be seen in Figure 1 below:

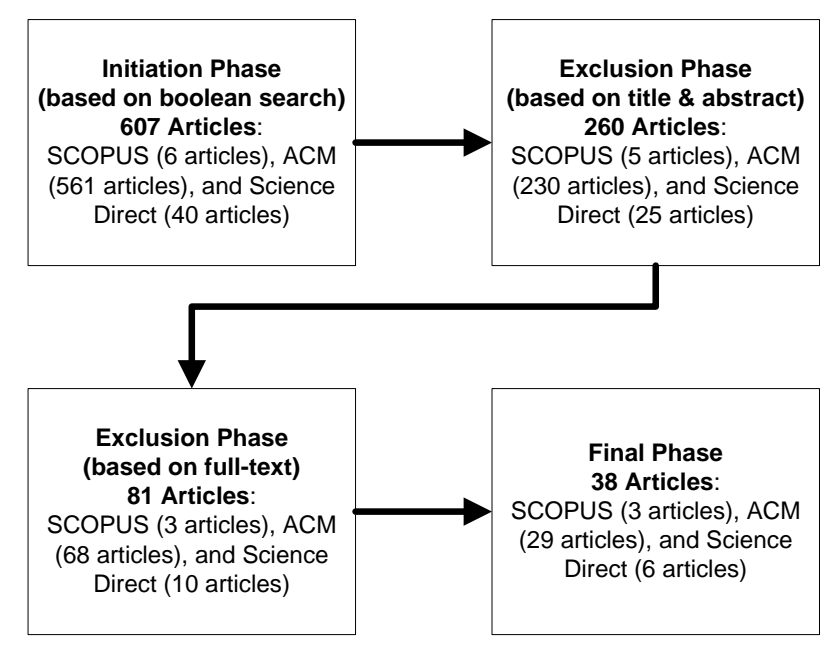

Figure 1. The selection phase of final articles

\section{Result and Analysis}

Based on the results of the Systematic Literature Review (SLR), an evaluation of the use of e-learning (learning system management) and trends (issues) regarding e-learning in the future can be seen in detail in table 2. In compiling the criteria of e-learning using Microsoft Excel to select and group criteria based on full paper from 38 articles.

Table 2. Criteria of E-Learning

\section{Criteria}

1.Platform

\section{Detail of Criteria}
1. MOOC [2]
2. Mobile Learning System [3]
3. Microsoft Teams [4]
4. MoodleRec [5]
5. Web 2.0 [6]
6. Mobile Learning Platform [7]
7. Mobile Teaching Platform [8]
8. Hybrid Teaching Platform [9]
9. Online Teaching Platform [10]
10. Learning Management System [11]
2. Evaluation
1. 5 Dimentional Evaluation Model
Model [2]
2. Kirkpatrick Model [12]
3. System Usability Scale [13] [4]
4. Technological Acceptance Model (TAM) [4] [14] [15]
5. SWOT Analysis [16]
6. Balanced Scorecard (BSC) [17]
7. Theory of Planned Behavior (TPB) [15]
8. Expectation Confirmation Model (ECM) [15] 


\section{Criteria}

\section{Detail of Criteria}

9. Flow Theory [15]

10. E-Learning System Success Model [11]

3. Evaluation

1. Service Quality [12]

2. Learning Attitude [2] [18]

3. Learning Process [2]

4. Learning Effect [2]

5. Learning Engagement [19]

6. User Satisfaction [13] [20]

7. Usability [13] [4] [21]

8. Utility of E-learning [20]

9. Gender [20]

10. Technology Adoption [14]

11. Teaching Quality [22]

12. Learning Performance [23]

13. Technology Use [6]

14. Learning Enthusiasm [7]

15. Interest of Learning [7]

16. Student and Educator Attitude [24]

17. Cognitive Ability Development [24]

18. Educational Environment [25]

19. Intellectual Activity [25]

20. E-learning Personification [26]

21. E-Learning Experiences [27]

22. Student Concentration Level [28]

23. Effectiveness of Online Teaching [29]

24. E-learning effectiveness [16]

25. Organization, Pedagogical, Technology [17]

26. Perceived Satisfaction [11]

27. Perceived Usefullness [11]

28. Student Perception [30]

29. Student Readiness [30]

30. Academic Performance [25]

1. Convoutional Neural Network

4. Model [19]

2. BP Neural Network [22]

3. Internet $+[9]$

4. Self Directed Learning [27]

5. Emergency Remote Education [21]

6. Emergency Remote Teaching [18]

7. Personal Zed E-learning Model [31]
Criteria

\section{Detail of Criteria}

8. Emergency Remote Learning (ERL) [32]

5. Approach 1. Microteaching Method [7]

2. Flipped Classroom [23]

3. Virtual Classroom [33]

4. Electroencophalography (EEG) [28]

5. Heart Rate Variability (HRV) [28]

6. Problem

1. Online Teaching is not Balanced [34]

2. Lack of Rational Introspection

[34]

3. Weakened Value of Educational Subject [34]

4. Social Isolation [21]

5. Teaching Environment [35]

6. Classroom Teaching [35]

7. Student Needs [35]

8. Readiness Use Digital Tools [36]

9. Lacking Capabilities [31]

10. Negative Performance [31]

11. Lack of Experience [37]

7. Trend and Usage of Social Web [38]

Challenge Semantic Web [38]

Intelligent Technology [38]

From the criteria that have been analyzed on the results of the SLR, it can be divided into 7 criteria, namely Platform, Evaluation Model, Evaluation, Model, Approach, Problem, and Trend and Challenge of elearning (learning management system). Based on these criteria can be detailed into more detail.

Platforms commonly used in e-learning implementation based on 38 articles, there are 10 platforms namely MOOC, Mobile Learning System, Microsoft Teams, MoodleRec, Web 2.0, Mobile Learning Platform, Mobile Teaching Platform, Hybrid Teaching Platform, Online Teaching Platform, and Learning Management System. Platform criteria are used to provide information about platforms that are often used in e-learning, so that they can be used as research preferences for the next.

In evaluating the use of e-learning models can use many models. There are 10 Evaluation Model criteria used to evaluate e-learning, namely 5 Dimensional Evaluation Model, Kirkpatrick Model, System Usability Scale, Technological Acceptance Model (TAM), SWOT Analysis, Balanced Scorecard (BSC), Theory of Planned Behavior (TPB), Expectation Confirmation Model (ECM), Flow Theory and E-learning System Success 
Model. These evaluation models can be used as a reference for research on the use of e-learning.

Other criteria used as a reference in evaluating elearning are 30 criteria: Service Quality, Learning Attitude, Learning Process, Learning Effect, Learning Engagement, User Satisfaction, Usability, Utility of Elearning, Gender, Technology Adoption, Teaching Quality, Learning Performance, Technology Use, Learning Enthusiasm, Interest of Learning, Student and Educator Attitude, Cognitive Ability Development, Educational Environment, Intellectual Activity, Elearning Personification, E-learning Experiences, Student Concentration Level, Effectiveness of Online Teaching, E-learning effectiveness, Organization, Pedagogical, and Technology, Perceived Satisfaction, Perceived Usefulness, Student Perception, Student Readiness. The criteria for evaluating e-learning can be used to build a new model for evaluating the use of e-learning, it does not have to use all evaluation criteria but can be combined according to the needs to be researched..

In addition, there are 7 models used in modeling e-learning, namely: Convoutional Neural Network, BP Neural Network, Internet + , Self Directed Learning, Emergency Remote Education, Emergency Remote Teaching, Personal Zed E-learning Model, and Emergency Remote Learning (ERL). The e-learning models that are currently being used can be used as a reference in implementing e-learning at various levels of education.

There are 5 approaches in implementing elearning, namely Microteaching Method, Flipped Classroom, Virtual Classroom, Electroencophalography (EEG) and Heart Reate Variability (HRV). Approach criteria are used to find out what methods have been used in several studies in e-learning.

In the implementation of e-learning, there will be many problems, based on studies from 38 articles, there are 11 problems from the implementation of e-learning, namely Online Teaching is not Balanced, Lack of Rational Introspection, Weakened Value of Educational Subject, Social Isolation, Teaching Environment, Classroom Teaching, Student Needs, Readiness Use Digital Tools, Lacking Capabilities, Negative Performance, Lack of Experience. The criteria for this problem can indicate problems that are often faced in the implementation of e-learning.

The last criteria discusses the trends and challenges in implementing e-learning, there are 3 trend and challenge criteria, namely: Usage of Social Web, Semantic Web, and Intelligent Technology. This criteria can be used as inspiration in conducting research on elearning implementation.

The 7 criteria that have been described in detail can provide an overview of continued research on elearning regarding the development of a new framework for the implementation of e-learning. In addition, these criteria can be used as reference material in evaluation discussions, evaluation models, platforms and approaches that can be used in research on e-learning applied at various levels of education.

\section{Discussion}

First, in the application of e-learning, it is necessary to review which evaluation method is the most appropriate for use at each level of education. Second, platforms that are suitable for use in the application of e-learning need to be studied further based on compatibility based on certain subjects. Third, the 30 evaluation criteria that can be used to evaluate the use of e-learning can be used to model new forms of e-learning that are more suitable. Fourth, there are many problems that arise from the use of e-learning that must be avoided from the use of elearning. Fifth, there are trends and challenges that can be tried for the implementation of e-learning in the future.

\section{Conclusion}

This study uses data based on 3 sources, namely Scopus, ACM and the Science Direct database, which produces 38 articles that have conformity based on research questions that are adapted to the boolean search used. Based on the summary, it was found 7 criteria in the implementation of e-learning, namely platforms, evaluation models, evaluations, models, approaches, problems, trends and challenges. Based on these 7 criteria, it can be used to build an e-learning model that is suitable for application at various levels of education. For further research, data from other research databases can be used apart from the 3 databases (Scopus, ACM and Science Direct) that have been used in this Systematic Literature Review (SLR)

\section{References}

[1] R. R. Suryono, B. Purwandari, and I. Budi, "Peer to peer (P2P) lending problems and potential solutions: A systematic literature review," Procedia Comput. Sci., vol. 161, pp. 204-214, 2019, doi: 10.1016/j.procs.2019.11.116.

[2] J. Li, "Construction of modern educational technology MOOC platform based on courseware resource storage system," Int. J. Emerg. Technol. Learn., vol. 12, no. 9, pp. 105116, 2017, doi: 10.3991/ijet.v12.i09.7491.

[3] J. C.-Y. Sun and K.-Y. Chang, "Design and development of a location-based mobile learning system to facilitate English learning," Univers. Access Inf. Soc., vol. 15, no. 3, pp. 345-357, 2016, doi: 10.1007/s10209-014-0392-x.

[4] D. Pal and V. Vanijja, "Perceived usability evaluation of Microsoft Teams as an online learning platform during COVID-19 using system usability scale and technology acceptance model in India," Child. Youth Serv. Rev., vol. 119, p. 105535, 2020, doi: https://doi.org/10.1016/j.childyouth.2020.105535

[5] C. De Medio, C. Limongelli, F. Sciarrone, and M. Temperini, "MoodleREC: A recommendation system for creating courses using the moodle e- 
learning platform," Comput. Human Behav, vol. 104, p. 106168, 2020, doi: https://doi.org/10.1016/j.chb.2019.106168.

[6] A. Krouska, C. Troussas, and C. Sgouropoulou, "Usability and Educational Affordance of Web 2.0 Tools from Teachers' Perspectives," in 24th Pan-Hellenic Conference on Informatics, 2020, pp. 107-110, doi: 10.1145/3437120.3437286.

[7] B. Song, Y. Sun, J. Guo, D. Zhao, and J. Tan, "Application of Case Teaching Method and Microteaching Method in Experimental Teaching Based on Wechat Platform," in Proceedings of the 2021 International Conference on Bioinformatics and Intelligent Computing, 2021, pp. 407-411, doi: 10.1145/3448748.3448988.

[8] C. Fan and J. Liu, "An Analysis of Russian Language and Culture Teaching under the Information Mobile Teaching Platform," in 2021 2nd Asia-Pacific Conference on Image Processing, Electronics and Computers, 2021, pp. 352-355, doi: 10.1145/3452446.3452537.

[9] Y. Liu, "Design and Application of Hybrid Teaching Platform Based on Internet +," in 2021 2nd International Conference on Computers, Information Processing and Advanced Education, 2021, pp. 1490-1493, doi: 10.1145/3456887.3459706.

[10] S. Li, Y. Yu, and S. Liu, "The Use of Online Teaching Platforms during CoVID-19 in China," 2021, doi: 10.1145/3465631.3465869.

[11] A. Rosetta, M. Agatha Priska, E. Muslim, and M. Rafi, "Evaluating the Success of E-Learning Systems and Strategy Creation: The Perspective of Students in Universitas Indonesia," in 2020 The 4th International Conference on Education and E-Learning, 2020, pp. 11-17, doi: 10.1145/3439147.3439155.

[12] M. K. Fadhilah, N. Surantha, and S. M. Isa, "Web-Based Evaluation System Using Kirkpatrick Model for High School Education (A Case Study for Vocational High School in Jakarta)," in Proceedings of 2018 International Conference on Information Management and Technology, ICIMTech 2018, 2018, pp. 166-171, doi: 10.1109/ICIMTech.2018.8528158.

[13] N. Harrati, I. Bouchrika, A. Tari, and A. Ladjailia, "Exploring user satisfaction for elearning systems via usage-based metrics and system usability scale analysis," Comput. Human Behav., vol. 61, pp. 463-471, 2016, doi: https://doi.org/10.1016/j.chb.2016.03.051.

[14] R. Scherer, F. Siddiq, and J. Tondeur, "The technology acceptance model (TAM): A metaanalytic structural equation modeling approach to explaining teachers' adoption of digital technology in education," Comput. Educ., vol. 128, pp. 13-35, 2019, doi: https://doi.org/10.1016/j.compedu.2018.09.009.

[15] D. Aulia Winarno, E. Muslim, M. Rafi, and A. Rosetta, "Quality Function Deployment
Approach to Optimize E-Learning Adoption among Lecturers in Universitas Indonesia," in 2020 The 4th International Conference on Education and E-Learning, 2020, pp. 161-166, doi: 10.1145/3439147.3439157.

[16] M. A. Safonov, S. S. Usov, and S. V. Arkhipov, "E-Learning Application Effectiveness in Higher Education. General Research Based on SWOT Analysis," in 2021 5th International Conference on Education and Multimedia Technology, 2021, pp. 207-212, doi: 10.1145/3481056.3481096.

[17] M. Agatha Priska, D. Aulia, E. Muslim, and L. Marcelina, "Developing a Framework to Evaluate E-Learning System at Higher Education in Indonesia," in 2020 The 4th International Conference on Education and E-Learning, 2020, pp. 27-32, doi: 10.1145/3439147.3439154.

[18] T. Crick, C. Knight, R. Watermeyer, and J. Goodall, "An Overview of the Impact of COVID-19 and 'Emergency Remote Teaching' on International CS Education Practitioners," in Proceedings of the 52nd ACM Technical Symposium on Computer Science Education, 2021, p. 1288, doi: 10.1145/3408877.3439680.

[19] Z. Li and Z. Zhan, "Integrated infrared imaging techniques and multi-model information via convolution neural network for learning engagement evaluation," Infrared Phys. Technol., vol. 109, 2020, doi: 10.1016/j.infrared.2020.103430.

[20] D. Eshun Yawson and F. Amofa Yamoah, "Gender variability in E-learning utility essentials: Evidence from a multi-generational higher education cohort," Comput. Human Behav., vol. 114, p. 106558, 2021, doi: https://doi.org/10.1016/j.chb.2020.106558.

[21] L. Marques, P. Matsubara, J. C. de Souza Filho, G. Gomes, B. Gadelha, and T. Conte, "Challenges and Learning from Remote Teaching of Usability and UX: An Experience Report," 2020, doi: 10.1145/3439961.3440003.

[22] C. Guo and Y. Liu, "BP Neural Network-Based Evaluation on University Teachers' Teaching Quality," in Proceedings of the 2020 3rd International Conference on E-Business, Information Management and Computer Science, 2020, pp. 285-289, doi: $10.1145 / 3453187.3453348$.

[23] H. K.Y. Ng, P. L.C. Lam, K. Chan, H. Leung, and S. Lai, "Flipping the Classroom: Will the Changes of Teachers Influence Learning Outcomes?," in 2020 The 4th International Conference on Education and E-Learning, 2020, pp. 42-45, doi: 10.1145/3439147.3439156.

[24] S. N. Kurbakova, Z. N. Volkova, and A. V Kurbakov, "Developing Students' Cognitive Abilities in E-Learning Environment," in 2021 12th International Conference on E-Education, E-Business, E-Management, and E-Learning, 2021, pp. 124-130, doi: 
10.1145/3450148.3450180.

[25] A. Shabunina, V. Shakhova, and L. Sorokina, "Emotional Resilience of Students in the Context of Distance Learning," in 2021 5th International Conference on Education and Multimedia Technology, 2021, pp. 345-354, doi: 10.1145/3481056.3481090.

[26] O. D. Shipunova, I. P. Berezovskaya, S. I. Kedich, N. V Popova, and N. Y. Kvashenko, "Intelligent Human Information Behavior in ELearning System," in 2021 2nd International Conference on Artificial Intelligence and Information Systems, New York, NY, USA: Association for Computing Machinery, 2021.

[27] F. Giuseffi, "Renewing Self-Directed Learning in E-Learning Experiences," ELearn, vol. 2021, no. 1, 2021, doi: 10.1145/3447871.3439736.

[28] Y. Nakagawa, P. Sripian, and M. Sugaya, "Evaluation of Distance Learning on Concentration and Relax by EEG and HRV: Poster Abstract," in Proceedings of the 18th Conference on Embedded Networked Sensor Systems, 2020, pp. 762-763, doi: $10.1145 / 3384419.3430602$.

[29] H. Deng, "Strategies to Improve the OnlineTeaching Effect of Colleges and Universities in the Post-Epidemic Era," in 2021 2nd International Conference on Computers, Information Processing and Advanced Education, 2021, pp. 786-789, doi: $10.1145 / 3456887.3457069$.

[30] A. Thi Van Pham and N. Thi Thao Ho, "The Implementation of E-Learning during the COVID-19 Pandemic in a Vocational Institution in Vietnam: An Investigation into Students' Perceptions and Readiness," in 2021 5th International Conference on Education and Multimedia Technology, 2021, pp. 234-239, doi: 10.1145/3481056.3481063.

[31] G. E. Acuna, L. A. Alvarez, J. Miraflores, and M. J. Samonte, "Towards the Development of an Adaptive E-Learning System with Chatbot Using Personalized E-Learning Model," in 2021 The 7th International Conference on Frontiers of Educational Technologies, 2021, pp. 120-125, doi: $10.1145 / 3473141.3473236$.

[32] X. Gui, Y. Li, and Y. Wu, "Teacher-Guardian Collaboration for Emergency Remote Learning in the COVID-19 Crisis," Proc. ACM Hum.Comput. Interact., vol. 5, no. CSCW2, 2021, doi: $10.1145 / 3479543$.

[33] T. Y. Huang and C. Huang, "Teaching and Learning through the Net," in 2020 The 4th International Conference on Education and ELearning, 2020, pp. 92-95, doi: $10.1145 / 3439147.3439182$.

[34] Y. Li, "Online Teaching of Higher Education in the Post-MOOC Era," in 2021 2nd International Conference on Computers, Information
Processing and Advanced Education, 2021, pp. 198-201, doi: 10.1145/3456887.3456931.

[35] D. Wang, "Novel Coronavirus Online Teaching in College During the Epidemic Period," in 2021 2nd International Conference on Computers, Information Processing and Advanced Education, 2021, pp. 108-112, doi: $10.1145 / 3456887.3456910$.

[36] O. Bardales Mendoza, T. Fernandez Bringas, and L. Saavedra Bendezú, "Perspectives of the Use of ICT for the Teaching-Learning Process among Peruvian University Students and Lecturers during the COVID-19 Pandemic," in 2020 2nd International Workshop on Artificial Intelligence and Education, 2020, pp. 49-53, doi: $10.1145 / 3447490.3447500$.

[37] C. Othman Abdullah and R. Mahmood Abdulla, "Evaluation of E-Learning in Higher Education during COVID-19 Pandemic: A Case Study in University of Sulaimani," in 2021 12th International Conference on E-Education, EBusiness, E-Management, and E-Learning, 2021, pp. 68-74, doi: 10.1145/3450148.3450176.

[38] T. Ivanova, V. Terzieva, and M. Ivanova, "Intelligent Technologies in E-Learning: Personalization and Interoperability," in International Conference on Computer Systems and Technologies '21, 2021, pp. 176-181, doi: 10.1145/3472410.3472427.

[39] Chaudhry, Ifat Sabir., Paquibut, Rene., Islam, Abu Reza., Chabchoub, Habib. Testing the success of real-time online delivery channel adopted by higher education institutions in the United Arab Emirates during the Covid-19 pandemic. International Journal of Educational Technology in Higher Education. 2021.

[40] Tautz D.,Sprenger D.A.,Schwaninger A.. Evaluation of four digital tools and their perceived impact on active learning, repetition and feedback in a large university class. Computers and Education. 2021

[41] Prasetyo, Yogi Tri., Ong, Ardvin Kester S., Krissianne Giero., Concepcion, Frances., Navata, Francheska Mikaela B. Determining Factors Affecting Acceptance of E-Learning Platforms during the COVID-19 Pandemic: Integrating Extended Technology Acceptance Model and DeLone \& McLean IS Success Model, Sustainability. 2021.

[42] Kitchenham, Barbara, O. Pearl Brereton, David Budgen, Mark Turner and Mohamed Khalil. "Lesson From Applying The Systematic Literature Review Process Within The Software Engineering Domain”. J Syst Softw 80 : 571 -58, 2007 